\title{
SIMULATION OF PHASE TRANSFORMATIONS IN HIGH CARBON PEARLITE STEEL AT VARIOUS COOLING RATES
}

\author{
S. A. Nevskii ${ }^{1}$, Yu. N. Simonov², V. E. Kormyshev', S. V. Konovalov ${ }^{3}$ \\ ${ }^{1}$ Siberian State Industrial University (Novokuznetsk, Russia) \\ 2 Perm National Research Polytechnic University (Perm, Russia) \\ ${ }_{3}^{3}$ Samara National Research University (Samara, Russia) \\ E-mail: ksv@ssau.ru
}

\section{AUTHOR'S INFO}

S. A. Nevskii, Cand. Eng., Assistant Prof., Dept. of Natural Science;

Yu. N. Simonov, Dr. Eng., Prof., Dept. of Metal Science, Laser and Thermal Treatment V. E. Kormyshev, Cand. Eng., Researcher, Research Dept.,

S. V. Konovalov, Dr. Eng., Prof., Dept. of Materials Technology and Aviation Material Science

\section{Key words:}

high carbon steel; continuous cooling transformation; transformation equilibrium temperature; volume fraction; dilatometric curves; simulation; Kolmogorov-Avrami equation.

\author{
A B S T RACT
}

The paper reports on the experimental research into the austenite decomposition in high carbon steel at a constant temperature and rates of cooling. The study was carried out by the methods of dilatometry, micro-durometry, optical and scanning microscopy. From the dilatometric curves it is apparent they are sufficiently presented by the Kolmogorov-Avrami equation in a temperature range from 700 to $550{ }^{\circ} \mathrm{C}$, and by the logistic function for temperatures ranging 500 to $250{ }^{\circ} \mathrm{C}$. The data of the dilatometric analysis were used to draw isothermal and continuous cooling transformation diagrams of phase conversions. It has been pointed out an isothermal diagram to comprise four C-curves of pearlite and bainite transformations, which are approximated by second- and third-degree polynomials. The critical temperatures of austenite, bainite, and martensite transformations have been determined, being 711,550 and $196^{\circ} \mathrm{C}$, respectively. Considering the data obtained experimentally, a mathematical model of austenite decomposition has been developed for a constant cooling rate, and volume fractions of structure-phase components estimated theoretically, demonstrating the congruence with experimental results. The suggested mathematical model can be adopted to calculate a structure-phase composition in industrial differential heat treatment of rails.

\section{Introduction}

Phase transformations in the system "iron-carbon" represent physical processes studied in detail both experimentally and theoretically [1-3]. So far, however, there has been little discussion about the mechanisms and kinetics of these transformations when heat treating the steel. Technologically, the thermal treatment of a steel deals with its heating up to temperatures of high-temperature phase (austenite) existence and further cooling in quenching agents [4]. Depending on the heat treatment conditions (set temperature, rate of cooling, thermophysical properties of a material to be processed and a quenching agent) there are diverse austenite decomposition mechanisms: ferrite, pearlite, bainite and martensite transformations [5-13]. A variety of phase transformation mechanisms implies the difference in their kinetics.

The key models developed relying on experimental data with the purpose to specify the kinetics of isothermal phase transformations are the Johnson-MehlAvrami-Kolmogorov equation (JMAK) [14-16] and the Kirkaldy-Venugopalan model (KV) [17]. The JMAKequation may be generalized for the case of two simultaneous phase transformations [18]. The prior research [19-22] has established these models characterize adequately diffusion-controlled transformations, e.g. pearlite and ferrite ones. The Koistinen and Marburger model (KM) has been proposed for the diffusion-free austenitemartensite transformation [23].
Simulating the bainite transformation kinetics [2426], it has been revealed that JMAK-type models fail to provide an appropriate explanation to this transformation and the authors suggested using the logistic function as an alternative. The work [27] has presented an improved model characterizing the formation of bainite structures under the isothermal heat treatment.

In a general case of several simultaneous phase transformations, a phase-field approach is applied to characterize their kinetics [28-31]; its mathematical model includes a partial differential equation for order parameters with more than ten difficult to identify coefficients. This approach has become widely adopted in fundamental studies to simulate phase transformations in the system "iron-carbon" [30, 31], nevertheless, its use for the description of quenching processes in rails is premature.

To sum up, to date there is no precise and simple model of isothermal diffusion and diffusion-free transformations for high and medium carbon steels. Therefore, this work aims to illustrate structure and phase transformations in pearlite rail steels using the phenomenological approach in the terminology [32]. This procedure determines the type and parameters of kinetic curves using dilatometrically obtained CTT diagrams and relies on the additivity principle when calculating structure and phase transformations in non-isothermal conditions, it compares projected and experimentally obtained data as well. In contrast to the phase-field model it is possible to use only two parameters within this approach. 


\section{Material and method of investigation}

As a material for the purpose of investigations we used a high carbon steel with the chemical composition similar to a pearlite rail steel (Table 1).

The dilatometry was conducted using a quenching dilatometer Linseis RITA L78 with horizontally located samples. To measure a real temperature of a sample to be analyzed, a thermocouple of the $\mathrm{K}$-type $(\mathrm{Ni}-\mathrm{NiCr})$ was applied, which was welded to the side surface of cylindrical samples. The inert high-purity gaseous helium was used to heat and cool. Dilatometric samples of interest were made as cylinders (height 9-11 mm, diameter 3-4 mm). A software package WIN - DIL, Linseis Data Evaluation and Maple was selected to collect and process data of experiments.

To determine the position of a critical point $\mathrm{Ac}_{1}$ (transformation start temperature) a sample made of steel under study was heated up to a temperature of $1000^{\circ} \mathrm{C}$ at a rate of $1.5^{\circ} \mathrm{C} / \mathrm{s}$. A temperature of heating to draw a CCT and an isothermal diagram was set $50{ }^{\circ} \mathrm{C}$ above the temperate the transformation is complete. A thermal range of the transformation was detected according to a point a tangent line detaches from a linear range of thermal expansion before and after the phase conversion. When plotting the CCT diagram, which shows the decomposition of overcooled steel austenite, samples made of steel under consideration were heated up to a temperature of $825^{\circ} \mathrm{C}$ at $1.5^{\circ} \mathrm{C} / \mathrm{s}$ and tempered for 15 minutes. Samples were cooled from the heating temperature up to a temperature of $30{ }^{\circ} \mathrm{C}$ at $100,30,10,7.5,5,1$ and $0.1{ }^{\circ} \mathrm{C} / \mathrm{s}$. A time from the point, a sample heated up to the heating temperature starts cooling, is indicated on the $\mathrm{X}$-axis of the CCT diagram presenting the decomposition of overcooled austenite.

When plotting an isothermal curve to characterize the decomposition of overcooled austenite, samples made of steel under study were heated up to a temperature of $825^{\circ} \mathrm{C}$ at $1.5^{\circ} \mathrm{C} / \mathrm{s}$ and tempered for 15 minutes. Samples were cooled from the heating temperature up to a temperature of isothermal tempering at $100{ }^{\circ} \mathrm{C} / \mathrm{s}$. The isothermal tempering in the range of overcooled austenite was carried out at temperatures of 700, 650, 600, 550, 500, $450,400,350,300$, and $250{ }^{\circ} \mathrm{C}$. A time from the point, the isothermal tempering begins, is indicated on the $\mathrm{X}$-axis of the isothermal curve demonstrating the decomposition of overcooled austenite. The limits of the transformation were also determined according to a point, a tangent line detaches from a linear range of thermal expansion before and after phase shift.

A volume fraction of the resolved austenite was estimated by a formula:

\begin{tabular}{|c|c|c|c|c|c|c|c|c|c|}
\hline \multicolumn{10}{|c|}{ Concentration of element, mass \% (balanced by Fe) } \\
\hline C & $\mathrm{Si}$ & $\mathrm{Mn}$ & $\mathrm{Cr}$ & $\mathrm{Ni}$ & V & $\mathrm{Al}$ & Mo & S & P \\
\hline 0.81 & 0.56 & 0.97 & 0.27 & 0.08 & 0.004 & 0.003 & 0.007 & 0.005 & 0.013 \\
\hline
\end{tabular}

$$
X=\frac{\Delta l-\Delta l_{\gamma}}{\Delta l_{\alpha}-\Delta l_{\gamma}},
$$

where $\Delta l_{\gamma}$ - absolute elongation prior the phase transformation; $\Delta l$ - current elongation; $\Delta l_{\alpha}-$ absolute elongation in the final point of the transformation.

Once dilatometric measurements have been completed, micro-sections were made on samples as they were subjected to the thermal treatment in specified conditions, a microstructure was investigated using the methods of optical and scanning microscopy, in addition, micro-durometry was carried out by the Vickers method.

The metallography was carried out on steel $80 \mathrm{GS}$ microsections using a $\times 500$ magnification inverted microscope Olympus GX 51. The obtained visual data were processed by a special hardware and software package SIAMS 700, as well as the software Olympus Stream Motion, version 1.8. To prepare microsections we pressed in samples by a setup CitoPress-10 (Struers, Дания) at a temperature of $120^{\circ} \mathrm{C}$. A total time for pressing in and cooling was set 5 minutes. Microsections were prepared by an automated machine Tegramin-30 (Struers, Дания). To study the structure a microsection was etched in a $3 \%$ alcohol solution of nitric acid.

\section{Experimental results and discussion}

Fig. 1 provides typical relations between the absolute elongation and volume fraction of the resolved austenite and time. Using the square procedure, we carried out the approximation with the help of Kolmogorov-Avrami equation

$$
X=1-\exp \left(-k t^{m}\right) \text {, }
$$

where $X$ - a volume fraction of the resolved austenite; $k, m-$ temperature and time depending parameters in the general case (see Fig. 1, $a, b$, curve 1) and a logistic function $X=\frac{1}{1+\exp (a+b \lg (t))}, a$ and $b-$ parameters of the logistic function (see Fig. 1, $a, b$, curve 2). The figure demonstrates that the Kolmogorov-Avrami equation (see Fig. $1, a$ ) at a tempering temperature of $600^{\circ} \mathrm{C}$ (a correlation coefficient of 0.99 ) provides a better explanation to experimental data than the logistic function (a correlation coefficient of 0.89 ).

At a soaking temperature of $250^{\circ} \mathrm{C}$ the observed dependences of resolved austenite fraction vs. time (see Fig. 1, $b$, curve 2) can be adequately characterized with the logistic function (a coefficient of correlation of 0.99 ). It is also true for temperatures of $300-500{ }^{\circ} \mathrm{C}$. As mentioned before, the dependence of volume fraction vs. time was similar for middle-carbon steels [24-26]. The absolute elongation tends to reduce on dilatometric curves in the given interval as the phase transformation is complete. Probably, it is a consequence of relaxing thermo-elastic stresses.

In a range of $700-600{ }^{\circ} \mathrm{C}$ the overcooled austenite resolves according to the pearlite mechanism, and it is 

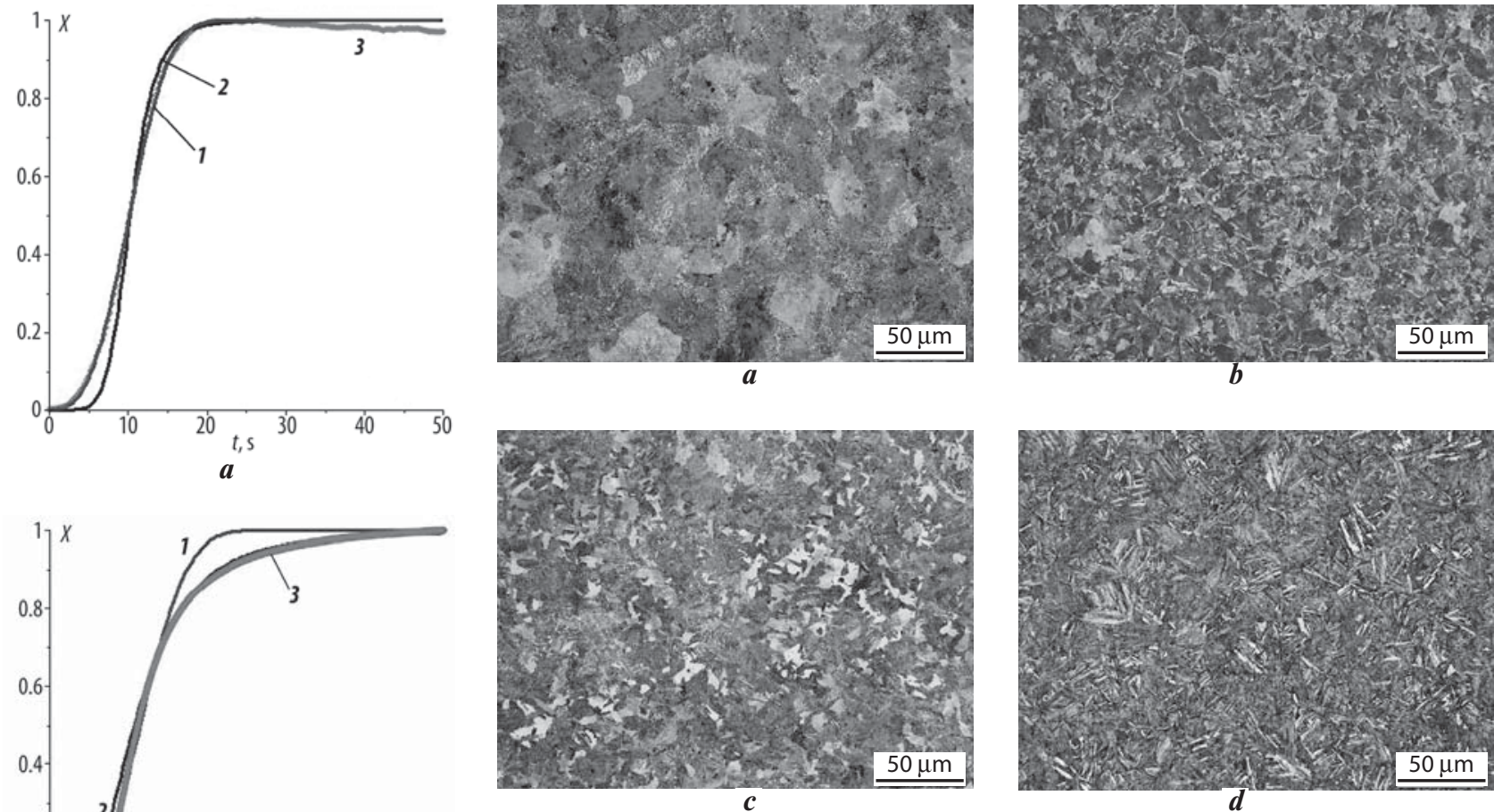

Fig. 2. Structure components of steel at various soaking temperatures: $a-700{ }^{\circ} \mathrm{C}$ (pearlite-type structures); $b-550{ }^{\circ} \mathrm{C}$ (a combination of pearlite and bainite); $c-450{ }^{\circ} \mathrm{C}$ (upper bainite structure, arrows indicate the residual austenite); $d-300{ }^{\circ} \mathrm{C}$ (lower bainite structure)

Fig. 1. The relation between the resolved austenite fraction and time at isothermal soaking $600{ }^{\circ} \mathrm{C}(a)$ and $250^{\circ} \mathrm{C}(b)$ : 1 - Kolmogorov-Avrami equation; $2-$ logistic function; 3 - experimental data

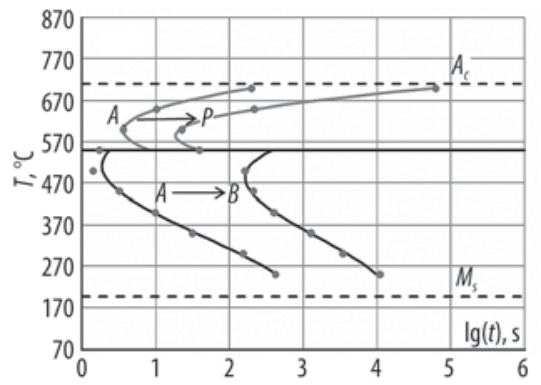
consisting of pearlite-cementite colonies. Once the dispersion of ferrite-carbide mixture increases (Fig. 2, a), the hardness tends to grow. The decomposition of the overcooled austenite at a temperature of $550{ }^{\circ} \mathrm{C}$ is the reason for the developing transformation according to pearlite and bainite mechanisms. Here a pearlite and bainite mixture forms (Fig. 2, $\boldsymbol{b}$ ).

The metallography realized by the methods of optical and scanning electron microscopy has highlighted a structure of the upper bainite forms in a temperature range of $500-400^{\circ} \mathrm{C}$. This structure might contain considerably big irregular round incorporations of retained austenite. Hardness increases from 340 to $428 \mathrm{HV}$ (Fig. 2, c).

An intermediate upper to lower bainite structure develops at a temperature of $350{ }^{\circ} \mathrm{C}$, at the same time, irregular round incorporations of retained austenite are detected in it, like in the upper bainite, as well as rectangular or sharp-cornered bright zones of retained austenite between platelets of bainite $\alpha$-phase. Here, hardness goes up to $520 \mathrm{HV}$. When isothermal tempering at temperatures of $300-250^{\circ} \mathrm{C}$, the overcooled austenite turns into the lower bainite (Fig. 2, d), which is made of sharp-cornered or

Fig. 3. Isothermal curve (TTT) of the overcooled austenite decomposition

rectangular bright zones of retained austenite and bainite $\alpha$-phase with inner carbide precipitates. The hardness of such structures is maximal provided that produced under isothermal decomposition and is estimated to be 597 and $689 \mathrm{HV}$, respectively.

In view of the data obtained in dilatometry, microdurometry and metallography studies we determined critical points $A c_{1}=711^{\circ} \mathrm{C} ; M s=196{ }^{\circ} \mathrm{C}$ and plotted an isothermal diagram for the overcooled austenite, which we used to find the start and end time of phase transformations (Fig. 3).

The plotted isothermal diagram demonstrates S-curves of pearlite transformation are well presented by parabolic functions (a correlation coefficient of 0.99):

$$
\begin{aligned}
& Y_{s}=60.3604-0.2000 T+1.6726 \cdot 10^{-4} T^{2}, \\
& Y_{f}=93.4498-0.3148 T+2.6875 \cdot 10^{-4} T^{2},
\end{aligned}
$$


where $Y=\lg (t)$, indexes s and $\mathrm{f}$ refer to start and end of phase transformation, respectively. S-curves of the bainite transformation are well approximated by a third degree polynomial function (correlation coefficients of 0.9 and 0.99 , respectively):

$$
\begin{aligned}
& Y_{s}=0.0383 T-1.4656 \cdot 10^{-4} T^{2}+1.4208 \cdot 10^{-7} T^{3}, \\
& Y_{f}=0.04864 T-1.7288 \cdot 10^{-4} T^{2}+1.6907 \cdot 10^{-7} T^{3},
\end{aligned}
$$

Further, equations (2) and (3) are used to estimate structure-phase compositions when accelerated cooling of rolled products.

\section{Mathematical model to describe the structure and phase composition formed when accelerated cooling rolled products}

The first objective within the mathematical simulation of structure and phase states when cooling is to find the relation between a product temperature and time. For this purpose it is necessary to solve a heat conductivity equation with boundary conditions of the third kind or use experimental curves of cooling. Cooling curves are adequately described by the linear equation:

$$
T=T_{0}-G t,
$$

where $G$-cooling rate, $T_{0}$ - input temperature, $t-$ time.

The second step represents the digitalization of a temperature function at time points $t_{n}=n \tau$, where temperature is stable in a range from $t_{n}$ to $t_{n+1}$, and estimated as $T_{n+1 / 2}=$ $=\left(T\left(t_{n}\right)+T\left(t_{n+1}\right)\right) / 2$. A degree of isothermal austenite transformation $\left(X_{1}\right)$, written as a function of transformation time $(\tau)$ to pearlite, is determined according to the Avrami equation; its coefficients are calculated by a formula:

$$
\begin{aligned}
& m(T)=\frac{-\lg \left(\ln \left(1-X_{s}\right) / \ln \left(1-X_{f}\right)\right)}{\lg \left(\frac{t_{s}(T)}{t_{f}(T)}\right)}, \\
& k(T)=-\frac{t_{s}(T)^{m(T)}}{\ln \left(1-X_{s}\right)} .
\end{aligned}
$$

A degree of isothermal austenite transformation into bainite was assessed by a logistic function; its coefficients are determined using the following formulae:

$$
a=\frac{\ln \left(\frac{\left(1 / X_{f}\right)-1}{\left(1 / X_{s}\right)-1}\right)}{\lg \left(\frac{t_{f}}{t_{s}}\right)}, b=\ln \left(\frac{1}{X_{s}}-1\right)-a \lg t_{s} .
$$

It was suggested fractures for the time points of start $t_{s}$ and end $t_{f}$ of pearlite and bainite transformations in these formulae are $X_{s}=1 \%$ and $X_{f}=99 \%$, respectively. The time limits of the phase transformation were determined by formulae (2) and (3).

Therefore, a plane of an isothermal diagram is divided into zones where the only phase of transformation can exist. Given the transformation is not isothermal; calculations are conducted according to a formula derived from the Steinberg-Sheile integral. In this case, a constant cooling process is presented as a series of isothermal tempering phases at temperatures of $T_{n+1 / 2}$ for a time from $t_{n}$ to $t_{n+1}$. Thus, a time of isothermal transformations $\left(\tau_{n}\right)$ can be determined by formulae (2) and (3) with respect to the certain transformation phase. A number of transformations can be stated by a relation $\mathrm{t}_{n} / \tau_{n}$ function $X$ for all previous points of time. The matter of the SteinbergSheile relation is that it is reduced to an equation in $X$ for the discrete transformation:

$$
\sum_{n=1}^{t} \frac{t_{n}}{\tau_{n}\left(X(t), T_{n}\right)} .
$$

For a continuous problem a sum (6) transforms to the integral, and we obtain an integral equation in $X(t)$ to determine the fraction. It is proposed to solve this equation (13) by the method derived from papers [33-35]. Volume fractions of austenite $-V_{1}$, pearlite $-V_{2}$, bainite $-V_{3}$, and martensite $-V_{4}$ are introduced. The sum total of structural elements fractions is $V_{1}+V_{2}+$ $+V_{3}+V_{4}=1$. The fraction of austenite for $n+1$ can be estimated provided that all structural components of the transformation are determined for $n+1$. We assume the only transformation of austenite to another phase is possible at time from $t_{n}$ to $t_{n+1}$, and use, therefore, intergraduated values of a fictive volume fraction of $i$-phase:

$$
X_{i}=\frac{V_{i}}{\left(V_{1}+V_{i}\right) V_{i}^{e q}},
$$

where $V_{i}^{e q}$ - equilibrium values of a volume fraction for structural components. Для перлита равновесное значение объемной доли будет иметь вид: $V_{2}^{e q}=$ $=\left(A c_{1}-T_{n+1 / 2}\right) /\left(A c_{1}-T_{B S}\right)$, а для бейнита $V_{3}^{e q}=$ $=\left(T_{B S}-T_{n+1 / 2}\right) /\left(T_{B S}-T_{B F}\right), T_{B F} \approx M_{S}$ [36], where $T_{B S}$, $T_{B F}$ - limit temperatures of the bainite transformation, respectively; $M_{S}$ - initial temperature of martensitic transformation.

Thus, the phase composition is determined according to the following algorithm:

1. Experimental data are necessary to determine temperatures: $A c_{1}, T_{B S}, T_{B F}, M_{S}$. A thermal trajectory is set $T(t)$, as well as volume fractions of phases: $V_{1}=1, V_{i}=0$ $(i=2,3,4)$ at the start time;

2. A time-cycle with a step $\Delta t$ is organized, values $T_{n+1 / 2}$, $X_{i}^{n}$ are known. A temperature region containing $T_{n+1 / 2}$ is determined. If it is not a martensite range, its number $i_{0}$ is recorded, a fictive time of the isothermal transformation is calculated $\tau_{i}{ }^{n}$ at a temperature $T_{n+1 / 2}$ and a fraction $X_{i}^{n}$ is determined using the following formulae:

$\begin{gathered}t_{i}^{n}=t_{s} \\ \text { mation; }\end{gathered}\left(\frac{\ln \left(1-X_{i}^{n}\right)}{\ln \left(1-X_{s}\right)}\right)^{1 / m(T)}-$ for the pearlite transfor-

$$
t_{i}^{n}=t_{s} 10^{\frac{1}{a} \ln \left(\frac{\left(1 / X_{i}^{n}\right)-1}{\left(1 / X_{s}\right)-1}\right)}-\text { for the bainite transforma- }
$$
tion. 
The next step is to find a fictive fraction $X_{i}^{n+1}$ by the Avrami equation or logistic function at a time $t=t_{i}^{n}+\tau$, and finally, a real volume fraction is calculated for a step $n+1$ :

$$
V_{i}^{n+1}=X_{i}^{n+1} V_{i}^{e q}\left(V_{1}^{n}+V_{i}^{n}\right) \text { and } V_{1}^{n+1}=1-\sum_{i=2}^{i_{0}} V_{i}^{n+1}
$$

The transformation is suggested to be complete at $V_{i}^{n+1} \leq 0$.

We adopted the above presented algorithm to develop a calculation procedure and determined the pattern of phases at various times and for different cooling rates. To verify the calculation outcomes the metallography research was carried out while samples were examined via optical microscopy and dilatometric studies were performed to find out how long phase transformations are for different rates of uninterrupted cooling. The data collected by the planimetric method of optical microscopy were used to detect a volume fraction of steel structure components. A period of phase transformations was established with the help of curves "elongation - time", in particular, a separation point of a tangent line from a linear part of thermal expansion before and after phase transformation.

Table 2 provides the results of calculations and experiments.

From the data of the table it is apparent the decomposition of austenite is compliant with the pearlite mechanism at cooling rates of $0.1{ }^{\circ} \mathrm{C} / \mathrm{s}$ and $1{ }^{\circ} \mathrm{C} / \mathrm{s}$; this phenomenon was proved to be true experimentally. The resolving of austenite at cooling rates from 5 to $7.5^{\circ} \mathrm{C} / \mathrm{s}$ flows according to the pearlite and martensite mechanisms. The estimated volume fractions of pearlite at cooling rates of $5{ }^{\circ} \mathrm{C} / \mathrm{s}$ and $7.5^{\circ} \mathrm{C} / \mathrm{s}$ are as high as 0.9 and 0.72 ; that is slightly above experimental values, whereas a fraction of pearlite is not so high as an experimental value for $G=10{ }^{\circ} \mathrm{C} / \mathrm{s}$. Such a discrepancy with experimental data might be the consequence of faulty measurements of temperature $A c_{1}$ [36] and dimensional changes of the austenite grain [37]. The estimated values of bainite fraction at $G=5^{\circ} \mathrm{C} / \mathrm{s}$ and $G=7.5^{\circ} \mathrm{C} / \mathrm{s}$ are 0.01

\begin{tabular}{|c|c|c|c|c|c|c|c|}
\hline \multicolumn{8}{|c|}{$\begin{array}{l}\text { Table 2. Comparison of estimated and experimental data } \\
\text { on the volume fraction of steel structure components } \\
\text { and periods of phase transformations }\end{array}$} \\
\hline \multirow[t]{2}{*}{$\begin{array}{l}\text { Cooling rate, } \\
{ }^{\circ} \mathrm{C} / \mathrm{s}\end{array}$} & \multicolumn{4}{|c|}{$\begin{array}{l}\text { Volume fraction (esti- } \\
\text { mation) }\end{array}$} & \multirow{2}{*}{\begin{tabular}{|c|}
$\begin{array}{c}\text { Volume frac- } \\
\text { tion of pearlite- } \\
\text { type structures } \\
\text { (experiment) }\end{array}$ \\
$X_{\exp }$ \\
\end{tabular}} & \multicolumn{2}{|c|}{$\begin{array}{l}\text { Period } \\
\text { of phase } \\
\text { transfor- } \\
\text { mations, }\end{array}$} \\
\hline & $V_{1}$ & $V_{2}$ & $V_{3}$ & $V_{4}$ & & Est. & Exp. \\
\hline 0.1 & 0.01 & \begin{tabular}{|l}
0.99 \\
\end{tabular} & 0 & 0 & & 530 & 572 \\
\hline 1 & 02 & 0.98 & 0 & 0 & & 76 & 69.3 \\
\hline 5 & 0.01 & 0.9 & 0.01 & 0.07 & & 20 & \\
\hline 7.5 & 0 & 0.72 & 0.05 & 0.23 & 0.40 & 16 & 15.7 \\
\hline 10 & 0.87 & 0.13 & 0 & 0 & 0.28 & 13 & 11.5 \\
\hline 30 & 0.0 & 0.09 & 0 & 0.91 & 0 & - & - \\
\hline \multicolumn{8}{|c|}{$\begin{array}{l}\text { Note: } V_{1}-\text { unresolved austenite, } V_{2}-\text { pearlite, } V_{3}-\text { bainite, } V_{4}- \\
\text { martensite, } X_{\text {exp }}-\text { experimental volume fraction of pearlite-type } \\
\text { structures. }\end{array}$} \\
\hline
\end{tabular}

and 0.05 , although it is undetectable by the methods of optical microscopy. Probably, bainite is beyond the microscope resolution in these conditions. The increasing a cooling rate to $30{ }^{\circ} \mathrm{C} / \mathrm{s}$ neutralizes completely bainite and pearlite transformations. A total amount of austenite turns into martensite.

Estimated periods of phase transformations (see Table 2) decrease as a cooling rate is reduced; this fact is in line with experimental results.

\section{Conclusion}

The study was focused on the processes of phase transformations in the rapidly cooled high-carbon steel. Analyzing dilatometric curves we found out the pearlite transformation kinetics is adequately characterized by the Kolmogorov-Avrami equation, and the logistic function can be applied to the bainite transformation. We plotted an isothermal diagram of phase transformations. This diagram shows start and end curves of austenite decomposition are well-approximated with second degree (pearlite transformation) and third degree polynomials (bainite transformation). The metallographic studies determined a bainite transition temperature of $550^{\circ} \mathrm{C}$. The critical points $A c 1=711^{\circ} \mathrm{C}$ and $M s=196^{\circ} \mathrm{C}$ were revealed in the dilatometric analysis.

Using the outcomes of experiments we proposed the mathematical model of phase transformations in the steel for a variety of cooling rates and the calculation program. The pearlite transformation was shown to be a dominant one for low cooling rates $0.1{ }^{\circ} \mathrm{C} / \mathrm{s}$ and $1{ }^{\circ} \mathrm{C} / \mathrm{s}$. At cooling rates of $G=5{ }^{\circ} \mathrm{C} / \mathrm{s}$ and $7.5^{\circ} \mathrm{C} / \mathrm{s}$ austenite tends to turn into pearlite and martensite; in addition, a fraction of pearlite structures is slightly higher than in experimental data, whereas a fraction of pearlite is as high as 0.13 for $G=10^{\circ} \mathrm{C} / \mathrm{s} 0.13$; that is lower than in experiments. This difference between simulation and experimental data results from the deficient measurements of temperature $A c_{1}$ and dimensional changes of the austenite grain. When increasing the rate of cooling up to $30^{\circ} \mathrm{C} / \mathrm{s}$ a total amount of austenite resolves according to the martensite mechanism, as shown experimentally.

The proposed algorithm and calculation program may be relevant for the developing a technology of thermal steel hardening.

\section{Acknowledgements}

The authors are grateful to Vladimir Sarychev, Egor Polevoy and Victor Gromov who took an active part in the preparation of the manuscript. This work is supported by the Russian Foundation for Basic Research (RFBR) Iproject number 19-32-60001] and President grant for State Support to young researches [grant number MK-118.2019.2].

\section{REFERENCES}

1. Fronstein N. Advanced High Strength Sheet Steels. Berlin: Springer, 2015. $396 \mathrm{p}$.

2. Zhao M., Song L., Fan X. The Boundary Theory of Phase Diagrams and Its Application, Berlin: Springer, 2011. 238 p. 
3. Fucheng Zhang, Zhinan Yang. Development of and Perspective on High-Performance Nanostructured Bainitic Bearing Steel. Engineering. 2019. Vol. 5. pp. 319-328. DOI: 10.1016/j. eng.2018.11.024

4. Sha W. Steels. Berlin: Springer, 2013. 268 p.

5. Ji-Cheng Zhao, Notis M.R. Continuous cooling transformation kinetics versus isothermal transformation kinetics of steels: a phenomenological rationalization of experimental observations. Materials Science and Engineering: R: Reports. 1995. Vol. 15. pp. 135-207. DOI: 10.1016/0927-796X(95)00183-2

6. Fei Peng, Yunbo Xu, Jiayu Li, Xingli Gu, Xu Wang. Interaction of martensite and bainite transformations and its dependence on quenching temperature in intercritical quenching and partitioning steels. Materials \& Design. 2019. Vol. 181. p. 107921. DOI: $10.1016 /$ j.matchar.2020.110244

7. Hehemann R. F., Kinsman K. R., Aaronson H. I. A debate on the bainite reaction. Metall. Trans. 1972. Vol. 3. No. 5. pp. 1077-1094. DOI: 10.1007/BF02642439

8. Bhadeshia H. K. D. H., Bainite In Steels. Transformations, Microstructure and Properties, Cambridge University Press, Cambridge, 2001. $454 \mathrm{p}$.

9. Caballero F. G., Miller M. K., Garcia-Mateo C., et al. New experimental evidence of the diffusionless transformation nature of bainite. J. Alloy. Compd. 2013. Vol. 577 (5). pp. S626S630. DOI: 10.1016/j.jallcom.2012.02.130

10. Borgenstam A., Hillert M., Ågren J. Metallographic evidence of carbon diffusion in the growth of bainite. Acta Mater. 2009. Vol. 57 (11). pp. 3242-3252. DOI: 10.1016/j.actamat.2009.03.026

11. Jun Lu, Hao Yu, Xiaoni Duan, Chenghao Song. Investigation of microstructural evolution and bainite transformation kinetics of multi-phase steel. Materials Science and Engineering: $A$. 2020. Vol. 774. pp. 138868 DOI: 10.1016/j.msea.2019.138868

12. Liu Z. C., Wang H. Y., Ren H. P. Shear-diffusion conformity mechanism of bainite transformation. In: Heat Treatment of Metals. 2006, pp. 36-42.

13. Razumov I. K. Possible Mechanisms of the Formation of Bainitic Colonies. Physics of the Solid State. 2019. Vol. 61. pp. 80-83. DOI: 10.1134/S1063783419020203

14. Johnson W. A., Mehl R. F. Reaction kinetics in processes of nucleation and growth. Trans. Am. Inst. Min. Metall. Eng. 1939. Vol. 135. pp. 416-458.

15. Avrami M. Kinetics of phase change. III: granulation, phase change and microstructure. J. Chem. Phys. 1941. Vol. 9. No. 2. pp. 177-184.

16. Kolmogorov A. N. On the statistical theory of metal crystallization. Izv. Akad. Nauk. SSSR Ser. Mat. 1937. No. 3. pp. 355-359.

17. Kirkaldy J. S., Venugopalan D. Prediction of microstructure and hardenability in low alloy steels, in: A. R. Marder, J. I. Goldstein (Eds.), International Conference on Phase Transformations in Ferrous Alloys. 1983. pp. 125-148.

18. Hao Zhao, Xiuli Hu, Junjia Cui, Zhongwen Xing. Kinetic model for the phase transformation of high-strength steel under arbitrary cooling conditions. Metals and Materials International. 2019. Vol. 25. pp. 381-395. DOI: $10.1007 / \mathrm{s} 12540-$ 018-0196-2

19. Lee S. J., Pavlina E. J., Tyne C. J. V. Kinetics modeling of austenite decomposition for an end-quenched 1045 steel. $M a-$ ter. Sci. Eng. A. 2010. Vol. 527. No. 13. pp. 3186-3194. DOI: 10.1016/j.msea.2010.01.081

20. Lee S. J., Lee Y. K. Finite element simulation of quench distortion in a low-alloy steel incorporating transformation kinetics. Acta Mater. 2008. Vol. 56 (7). pp. 1482-1490. DOI: 10.1016/j.actamat.2007.11.039

21. Åkerström P., Bergman G., Oldenburg M. Numerical implementation of a constitutive model for simulation of hot stamping. Model. Simul.Mater. Sci. Eng. 2007.Vol. 15(2).pp. 105-119. DOI: 10.1088/0965-0393/15/2/007

22. Hippchen P., Lipp A., Grass H., Craighero P. et al. Modelling kinetics of phase transformation for the indirect hot stamping process to focus on car body parts with tailored properties. Journal of Materials Processing Technology. 2016. Vol. 228. pp. 59-67. DOI: 10.1016/j.jmatprotec. 2015.01 .003

23. Koistinen D. P., Marburger R. E. A general equation prescribing the extent of the austenite-martensite transformation in pure iron carbon alloys and plain carbon steels. Acta Metall. 1959. Vol. 7 (1). pp. 59-60. DOI: 10.1016/00016160(59)90170-1

24. Yudin Yu. V., Maisuradze M. V., Kuklina A. A. Describing the isothermal bainitic transformation in structural steels by a logistical function. Steel in Translation. 2017. Vol. 47. pp. 213-218. DOI: 10.3103/S0967091217030160

25. Yudin Yu. V., Kuklina A. A., Lebedev P. D., Maisuradze M. V. Simulation of Isothermal Austenite Transformation in Steel. Steel in Translation. 2018. Vol. 48. pp. 684-689. DOI: 10.3103/S0967091218100133

26. Maisuradze M. V., Ryzhkov M. A., Yudin Yu. V., Kuklina A. A. Transformations of supercooled austenite in a promising highstrength steel under continuous cooling. Metal Science and Heat Treatment. 2017. Vol. 59. pp. 486-490. DOI: 10.1007/ s11041-017-0176-Z

27. Sidhu Gaganpreet, Srinivasan Seshasai, Bhole Sanjiwan. A Model for bainite formation at isothermal heat treatment conditions. Journal of Thermal Science and Engineering Applications. 2020. Vol. 12. p. 011006. DOI: 10.1115/1.4042861

28. Razumov I. K., Gornostyrev Yu. N., Katsnelson M. I. Effect of magnetism on kinetics of $\gamma \rightarrow \alpha$ transformation and pattern formation in iron. J. Phys.: Condens. Matter. 2013. Vol. 25. pp. 135401. DOI: $10.1088 / 0953-8984 / 25 / 13 / 135401$

29. Razumov I. K., Gornostyrev Yu. N., Katsnelson M. I. Autocatalytic mechanism of pearlite transformation in steel. Physical Review Applied. 2017. Vol. 7. pp. 014002. DOI: 10.1103/ PhysRevApplied.7.014002

30. Loginova I., Odqvist J., Amberg G., Agren J. The phase-field approach and solute drag modeling of the transition to massive $\gamma \rightarrow \alpha$ transformation in binary $\mathrm{Fe}-\mathrm{C}$ alloys. Acta Materialia. 2003. Vol. 51. pp. 1327-1339. DOI: 10.1016/S13596454(02)00527-X

31. Loginova I., Amberg G., Agren J. On the formation of Widmanstatten ferrite in binary $\mathrm{Fe}-\mathrm{C}$ phase-field approach. Acta Materialia. 2004. Vol. 52. pp. 4055-4063. DOI: 10.1016/j.actamat.2004.05.033

32. Kuziak R., Pidvysots'kyy V., Pernach M., Rauch L., Zygmunt T., Pietrzyk M. Selection of the best phase transformation model for optimization of manufacturing processes of pearlitic steel rails. Archives of Civil and Mechanical Engineering. 2019. Vol. 19. pp. 535-546.

33. Shah S. M. A., Khattak M. A., Asad M., Iqbala J., Badshahd S., Khan M. S. Numerical modeling of phase transformation during grinding process. Jurnal Teknologi. 2017. Vol. 79. pp. 33 - 41, DOI: 10.11113/jt.v79.10573

34. Sarychev V. D., Khaimzon B. B., Nevskii S. A., Il'yashchenko A. V., Grishunin V. A. Mathematical models of mechanisms for rolled products accelerated cooling. Izvestiya vuzov. Chernaya metallurgiya. 2018. Vol. 61. pp. 326-332. DOI: 10.17073/0368-0797-2018-4-326-332

35. Konovalov S., Chen X., Sarychev V., Nevskii S., Gromov V., Trtica M. Mathematical modeling of the concentrated energy flow effect on metallic materials. Metals. 2017. Vol. 7 (1). No. 4. pp. 1-18. DOI: $10.3390 /$ met7010004

36. Voronov A. N., Kvachkai T, Zadan V. T., Pavlush M. Computer modelling of austenite transformation at steel cooling. Izvestiya AN SSSR. Metally. 1991, Iss. 2. pp. 81-89.

37. Reti T., Fried Z., Felde I. Computer simulation of steel quenching process using a multi-phase transformation model. Computational Materials Science. 2001. Vol. 22. pp. 261-278. DOI: 10.1016/S0927-0256(01)00240-3 